\title{
Current and emerging therapies for the treatment of pancreatic cancer
}

This article was published in the following Dove Press journal:

OncoTargets and Therapy

13 July 2010

Number of times this article has been viewed

\section{Rebecca A Moss \\ Clifton Lee}

The Cancer Institute of New Jersey, New Brunswick, NJ, USA
Correspondence: Rebecca A Moss

The Cancer Institute of New Jersey,

195 Little Albany St, New Brunswick,

NJ 08903, USA

Tel $+\mathrm{I}-732-235-8663$

Fax + I-732-235-8808

Email mossr I@umdnj.edu
Abstract: Pancreatic adenocarcinoma carries a dismal prognosis and remains a significant cause of cancer morbidity and mortality. Most patients survive less than 1 year; chemotherapeutic options prolong life minimally. The best chance for long-term survival is complete resection, which offers a 3 -year survival of only $15 \%$. Most patients who do undergo resection will go on to die of their disease. Research in chemotherapy for metastatic disease has made only modest progress and the standard of care remains the purine analog gemcitabine. For resectable pancreatic cancer, presumed micrometastases provide the rationale for adjuvant chemotherapy and chemoradiation (CRT) to supplement surgical management. Numerous randomized control trials, none definitive, of adjuvant chemotherapy and CRT have been conducted and are summarized in this review, along with recent developments in how unresectable disease can be subcategorized according to the potential for eventual curative resection. This review will also emphasize palliative care and discuss some avenues of research that show early promise.

Keywords: neoadjuvant therapy, palliative care adeno carcinoma, mortality

\section{Introduction}

Despite all efforts at developing effective therapy, pancreatic adenocarcinoma carries a dismal prognosis ${ }^{1}$ and remains a significant cause of cancer morbidity and mortality. There is no screening test for this disease, and patients are generally only identified when already symptomatic with weight loss, back or abdominal pain, or obstructive jaundice. Most patients survive less than 1 year; chemotherapeutic options prolong life minimally. The best chance for long-term survival is complete resection, which offers a 3-year survival of only $15 \% .^{2}$ Most patients who do undergo resection will go on to die of their disease ${ }^{3}$ (see Figure 1). Research in chemotherapy for metastatic disease has made only modest progress and the standard of diabetes mellitus care remains the purine analog gemcitabine. ${ }^{4}$

Well-established risk factors for pancreatic cancer include smoking and family history. There is a slight increased risk with some familial cancer syndromes, including Lynch syndrome ${ }^{5}$ and $B R C A 2$ mutations. ${ }^{6}$ Recently, obesity has been identified as a modifiable risk factor in the development of and mortality from pancreatic cancer. ${ }^{7-10}$ There are no screening recommendations for this disease.

In this article, we will review current treatments for pancreatic cancer. We will discuss adjuvant therapy and recent developments in how unresectable disease can be subcategorized according to the potential for eventual curative resection. Considering the bleak prognosis of this disease, an important challenge is maintaining quality of remaining life with multidisciplinary support. Therefore, we will emphasize palliative care. 


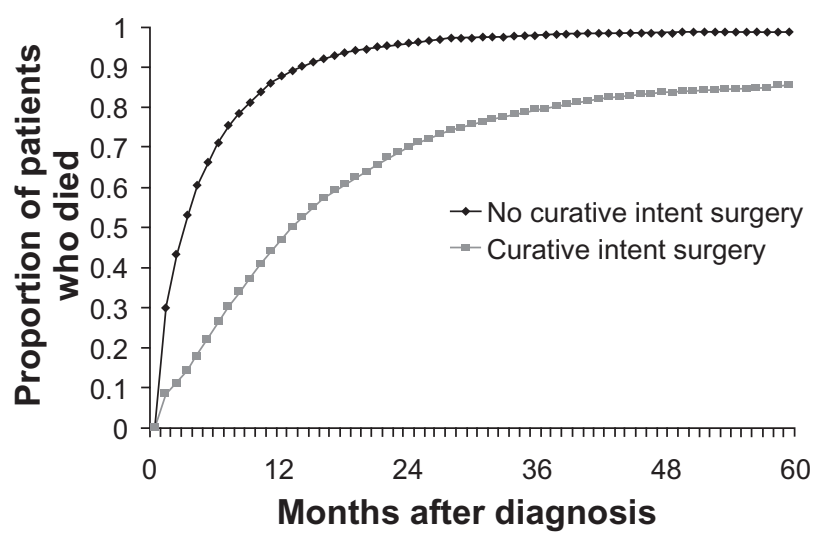

Figure I Survival of patients with pancreatic cancer categorized by the receipt of curative intent surgery. Copyright (C) 2007. Reproduced with permission from Shaib Y, Davila J, Naumann C, El-Serag H. The impact of curative intent surgery on the survival of pancreatic cancer patients: a U.S. Population-based study. Am J Gastroenterol. 2007;102(7):1377-1382.

Finally, we will discuss some avenues of research that show early promise as our understanding of the biology of this devastating disease improves.

\section{Managing resectable disease}

Surgical resection for treatment of localized pancreatic cancer is currently the best chance for cure. Unfortunately, up to
$85 \%{ }^{11}$ of patients initially present in advanced or metastatic stages, and curative resection is only possible in roughly $13 \%$ of patients. ${ }^{1}$ Even in patients who present with more favorable disease and undergo surgery with curative intent, there is a high rate of relapse, ${ }^{12,13}$ with high local recurrence rates of up to $50 \%$ following surgery alone ${ }^{14}$ leading to a 5 -year survival rate of under $5 \%{ }^{1}$ This aggressive recurrence pattern is highly suggestive of the presence of micrometastases at the time of surgery. ${ }^{11}$ For resectable pancreatic cancer, presumed micrometastases provide the rationale for adjuvant chemotherapy and chemoradiation (CRT) to supplement surgical management. Numerous randomized control trials, none definitive, of adjuvant chemotherapy and CRT have been conducted, summarized in Table 1.

\section{Adjuvant CRT and chemotherapy: regional differences}

The earliest prospective randomized trial to suggest a survival benefit from the addition of postoperative CRT was the GastroIntestinal Study Group (GITSG) trial. ${ }^{15}$ Patients receiving bolus fluorouracil (5-FU) and a split course of 20 Gy radiation for 2 cycles after primary surgery followed by maintenance

Table I Randomized control trials of adjuvant chemotherapy and CRT

\begin{tabular}{|c|c|c|c|c|c|c|c|}
\hline Study & Year & Chemo & RT & $\begin{array}{l}\text { No. of } \\
\text { patients }\end{array}$ & MOS & $\begin{array}{l}\text { 2-yr survival } \\
\text { rate, } \%\end{array}$ & $P$ value \\
\hline \multirow[t]{2}{*}{ GITSG Kalser ${ }^{15}$} & 1985 & $5-\mathrm{FURT} \rightarrow 5-\mathrm{FU}$ & $40 \mathrm{~Gy}$ & 21 & 20 & 42 & 0.035 \\
\hline & & Observation & & 22 & 11 & 15 & \\
\hline \multirow[t]{2}{*}{ Bakkevold et al ${ }^{19}$} & 1993 & AMF & & 30 & 23 & 43 & 0.009 \\
\hline & & Observation & & 31 & 11 & 32 & \\
\hline \multirow[t]{2}{*}{ EORTC Klinkenbijl et al ${ }^{16}$} & 1999 & 5 -FURT & $60 \mathrm{~Gy}$ & 60 & 17.1 & 37 & 0.099 \\
\hline & & Observation & & 54 & 12.6 & 23 & \\
\hline \multirow[t]{4}{*}{ ESPAC-I Neoptolemos et al $\left.\right|^{18}$} & 2004 & 5-FURT & $40 \mathrm{~Gy}$ & 145 & 15.9 & 29 & 0.053 \\
\hline & & Observation & & 144 & 17.9 & 41 & \\
\hline & & 5-FU/LV & & 147 & 20.1 & 40 & 0.009 \\
\hline & & Observation & & 142 & 15.5 & 30 & \\
\hline \multirow[t]{6}{*}{ ROTG 9704 Regine et $\mathrm{a}^{39}$} & 2006 & All patients & & & & & \\
\hline & & $\mathrm{GEM} \rightarrow 5$-FURT $\rightarrow$ GEM & $50.4 \mathrm{~Gy}$ & 221 & 18.8 & & 0.15 \\
\hline & & 5 -FU $\rightarrow 5$-FURT $\rightarrow 5$-FU & & 221 & 16.9 & & \\
\hline & & Pancreas head & & & & & \\
\hline & & GEM $\rightarrow 5$-FURT $\rightarrow$ GEM & $50.4 \mathrm{~Gy}$ & 187 & 20.6 & & 0.033 \\
\hline & & $5-\mathrm{FU} \rightarrow 5-\mathrm{FURT} \rightarrow 5$-FU & & 194 & 16.9 & & \\
\hline \multirow[t]{2}{*}{ Kosuge et $\mathrm{a}^{21}$} & 2006 & $5-F U / C D D P$ & & 45 & 12.5 & & 0.94 \\
\hline & & Observation & & 44 & 15.8 & & \\
\hline \multirow[t]{2}{*}{ CONKO-00I Oettle et $\mathrm{al}^{22}$} & 2007 & GEM & & 179 & 22.1 & 47.5 & 0.06 \\
\hline & & Observation & & 175 & 20.2 & 42 & \\
\hline Kosuge et $\mathrm{a}^{21} /$ Ueno et $\mathrm{a}^{23}$ & 2007 & GEM & & 58 & 22.3 & 48.3 & 0.29 \\
\hline (abstract) & & Observation & & 60 & 18.4 & 39.8 & \\
\hline \multirow[t]{2}{*}{ ESPAC-3 Neoptolemos et a $\left.\right|^{24}$} & 2009 & 5-FU/LV & & 551 & 23.0 & & \\
\hline & & GEM & & 537 & 23.6 & & \\
\hline
\end{tabular}

Abbreviations: AMF, adriamycin/mitomycin CRT, chemoradiation; RT, radiation therapy; MOS, median survival overall; GITSG, Gastrointestinal Tumor Study Group; 5-FURT, fluorouracil and radiation; CDDP, cisplatin; EORTC, European Organization for Research and Treatment of Cancer; ESPAC, Europen Study Group For Pancreatic Cancer; 5-FU, fluorouracil; GEM, gemcitabine; LV, leucovorin; RTOG, Radiation Therapy Oncology Group; CONKO, German Study Group for Pancreatic Cancer. 
5-FU were reported to have a median overall survival (OS) of 20 months compared with 11 months with surgery alone. Though this study had a small sample size, early termination, and suboptimal radiation dosing, it was still highly influential, making concurrent adjuvant CRT the standard of care in the United States. In Europe, however, the European Organization for Research and Treatment of Cancer (EORTC) conducted a similar study comparing postoperative radiation with continuous infusion of 5-FU without subsequent chemotherapy maintenance. The median duration of survival was 19.0 months for the observation group and 24.5 months in the treatment group but the study did not reach statistical significance (two-tailed test, $P=0.208$ ) ${ }^{16}$ Thus, CRT did not become standard practice in Europe. However, the European study may have an inappropriate statistical design that biased against the detection of treatment effects. As a follow up to the positive GITSG study, a one-tailed rather than two-tailed test would have been appropriate and would have brought the results to significance $(P=0.049)$ in favor of CRT. ${ }^{17}$ This finding is even more robust considering that nearly $20 \%$ of the patients assigned to the CRT arm were not even treated, which would further bias the study against CRT.

Despite these criticisms, the debate continued. A second line of evidence has led most European clinicians to adopt chemotherapy rather than CRT as the current standard of care. The Europen Study Group for Pancreatic Cancer-1 (ESPAC-1) study showed a near-doubling of benefit for adjuvant chemotherapy with infusional 5-FU and leucovorin (LV), but no benefit with $5-\mathrm{FU}$ and radiation. This trial had a $2 \times 2$ factorial design comparing CRT to observation and infusional 5-FU/LV to observation. The estimated 5-year survival rate was $10 \%$ among patients assigned to receive CRT and $20 \%$ among patients who did not receive CRT $(P=0.05) .{ }^{18}$ However, this study may have suffered from selection bias and an insufficient sample size for a $2 \times 2$ study design. ${ }^{19}$ In addition, there was an excessive rate of local recurrence in the CRT arm, suggesting the radiation schedule was suboptimal. ${ }^{20}$

\section{Outside the United States, adjuvant chemotherapy remains the focus of trials}

Trials of adjuvant chemotherapy alone have continued subsequent to the EORTC and ESPAC-1 trials. A trial of 5-FU and cisplatin based in Japan showed no difference, and possibly harm in patients receiving this aggressive adjuvant chemotherapy regimen. ${ }^{21}$ The CONKO-001 trial of 368 patients showed a benefit in disease-free survival (DFS) for patients receiving gemcitabine compared with observation (median DFS, 13.4 months vs 6.9 months), but only a small and insignificant difference in $\mathrm{OS}^{22} \mathrm{~A}$ similar but smaller study in Japan did not reach statistical significance. ${ }^{23}$ At the 2009 American Society of Clinical Oncology (ASCO) annual meeting, Neoptolemos et $\mathrm{al}^{24}$ presented the results of ESPAC-3 trial in which patients were randomized 1:1 to adjuvant chemotherapy with 5 -FU/LV bolus vs gemcitabine. The OS was 23.0 months vs 23.6 months $(P=0.39)$ in this large study, with the conclusion that gemcitabine is not superior to 5-FU in the adjuvant setting. ${ }^{24}$ However, ESPAC-4, currently enrolling in Europe, is based on the assumption that gemcitabine is superior to 5-FU in the adjuvant therapy setting. ESPAC-4 will directly compare gemcitabine to a gemcitabine-capecitabine combination after resection of pancreatic cancer, again without radiation. Enrollment of more than 1,000 patients is planned. Unfortunately, there will be no comparison of adjuvant CRT to chemotherapy alone, maintaining the regional differences in both practice and clinical trials.

\section{Can locally advanced disease be resected?}

The most significant advance in treating locally advanced disease has been the recognition that treatment has potential to downstage tumors to allow secondary surgical manage-

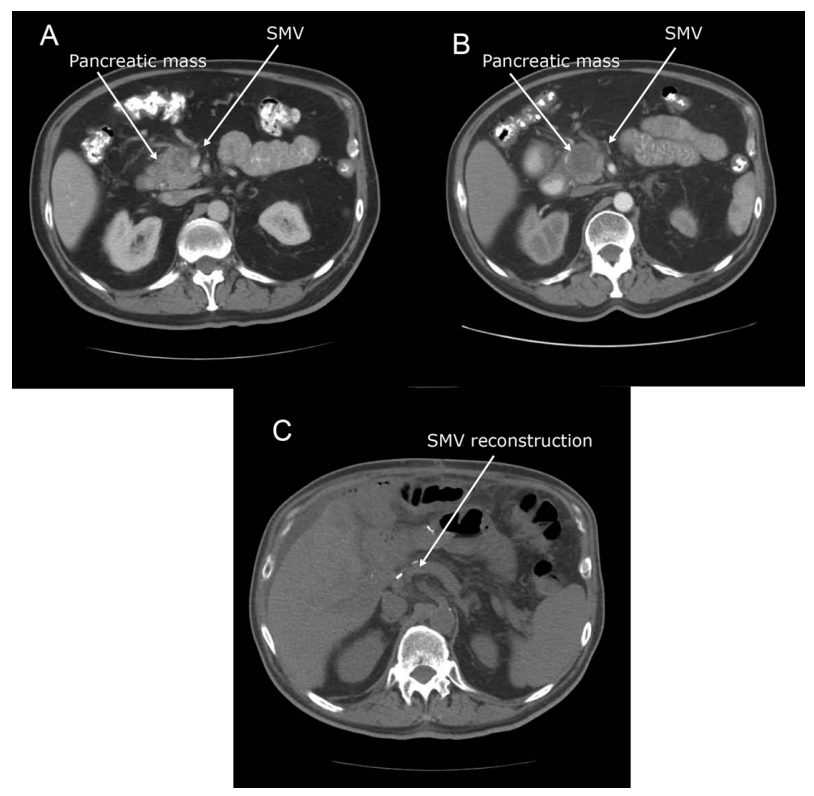

Figure 2 Downstaging with neoadjuvant therapy: 59-year-old man with a $2.2 \times$ $1.8 \mathrm{~cm}$ pancreatic head mass found to be pancreatic adenocarcinoma on biopsy A) Pretreatment scan. Note severe SMV impingement, which fits criteria for borderline resectable disease B) Post-treatment scan. The patient was reated with neoadjuvant capecitabine $1500 \mathrm{mg}$ po bid and concurrent radiation. The SMV is less confined; the pancreas mass remains similar in size. C) Post-operative scan. The patient underwent pancreaticoduodenectomy with jugular SMV reconstruction. 
Table 2 Criteria for defining resectability status ${ }^{25,26}$

\begin{tabular}{|c|c|c|c|}
\hline & Resectable & $\begin{array}{l}\text { Borderline } \\
\text { resectable }\end{array}$ & Unresectable \\
\hline Venous & $\begin{array}{l}\text { Patent SMV } \\
\text { and portal vein }\end{array}$ & $\begin{array}{l}\text { Severe SMV } \\
\text { impingement or } \\
\text { reconstructable } \\
\text { SMV occlusion }\end{array}$ & $\begin{array}{l}\text { Unreconstructable } \\
\text { SMV/portal } \\
\text { occlusion } \\
\text { Greater than } 180^{\circ} \\
\text { SMA encasement }\end{array}$ \\
\hline \multirow[t]{4}{*}{ Arterial } & $\begin{array}{l}\text { Clear fat plane } \\
\text { around celiac } \\
\mathrm{A} \text { and SMA }\end{array}$ & $\begin{array}{l}\text { Less than } 180^{\circ} \\
\text { abutment of SMA, } \\
\text { reconstructable } \\
\text { encasement of SMA }\end{array}$ & $\begin{array}{l}\text { Greater than } 180^{\circ} \\
\text { SMA encasement }\end{array}$ \\
\hline & & $\begin{array}{l}\text { Reconstructable } \\
\text { abutment or } \\
\text { encasement of } \\
\text { hepatic artery }\end{array}$ & $\begin{array}{l}\text { Unreconstructable } \\
\text { SMA involvement }\end{array}$ \\
\hline & & & $\begin{array}{l}\text { Any celiac } \\
\text { abutment (head } \\
\text { mass) }\end{array}$ \\
\hline & & & $\begin{array}{l}\text { Greater than } 180^{\circ} \\
\text { SMA encasement } \\
\text { (body mass) }\end{array}$ \\
\hline Aorta & & & $\begin{array}{l}\text { Aortic invasion or } \\
\text { encasement }\end{array}$ \\
\hline Mets & $\begin{array}{l}\text { No distant } \\
\text { metastases }\end{array}$ & & $\begin{array}{l}\text { Distant } \\
\text { metastases } \\
\text { Metastases to LN } \\
\text { beyond field of } \\
\text { resection }\end{array}$ \\
\hline
\end{tabular}

ment $^{25}$ (see Figure 2). With this new paradigm of possibly downstaging tumors, locally advanced pancreatic cancer is categorized into 2 distinct groups: borderline resectable and unresectable, summarized in Table $2 .{ }^{25,26}$ Before these criteria were established, the standard of care for locally advanced disease had been concurrent CRT without expectation of making the disease resectable. ${ }^{27,28}$ These criteria allow borderline resectable disease with no vascular involvement to be distinguished from locally advanced unresectable disease with vascular involvement. Both these categories may benefit from neoadjuvant therapy, and secondary resection has emerged as an important therapeutic goal.

Early attempts at preoperative treatment using chemotherapy, ${ }^{29}$ radiotherapy, ${ }^{30}$ and $\mathrm{CRT}^{31}$ demonstrated that neoadjuvant treatment of previously inoperable pancreatic tumors may result in potentially curative secondary surgery. In this scenario, the chief objective of neoadjuvant therapy for borderline resectable patients is to induce a partial tumor response and, therefore, increase the likelihood of complete resection with negative margins. Additionally, exposure of the tumor to chemotherapeutic agents before resection allows for the sensitivity of the tumor to those agents to be assessed. Tumors that progress despite therapy may be those with aggressive biology that would progress even if resected and treated adjuvantly. Those patients who progress during neoadjuvant treatment are, therefore, spared the morbidity and mortality of major surgery. On the other hand, patients with favorable responses to preoperative therapy as demonstrated by radiographic tumor regression and improvement in serum tumor marker levels may have the best chance for an $\mathrm{R} 0$ resection and a favorable long-term outcome. $^{25}$

\section{Might neoadjuvant CRT improve resectability and survival?}

Preoperative therapy for locally advanced pancreatic cancer has been the focus of multiple phase II trials. Several of these trials have demonstrated encouraging rates of secondary resection. ${ }^{32,33}$ The emergence of borderline resectable disease as a separate category in trials in 2002 (see Table 3) has opened the possibility of evaluating the role of neoadjuvant CRT. Previously, trials failed to distinguish borderline resectable from resectable or borderline unresectable disease. In the single study to address this subgroup, Brown et $\mathrm{al}^{34}$ tested a combination of radiosensitizing agents with $50.4 \mathrm{~Gy}$ of radiation in 13 patients with borderline resectable disease. All patients underwent secondary surgery with intent for cure. Eighty-five percent (11 patients) had complete, or R0, resections, which led to a 2 -year survival of $69 \%(n=9)$ and 8 patients disease-free at 2 years.

In a phase II trial by Massucco et $\mathrm{al}^{33}$ of neoadjuvant gemcitabine with 45 Gy radiation in borderline resectable and unresectable locally advanced disease, 8 patients who had unresectable disease responded favorably to neoadjuvant therapy and went on to resection. These patients had similar OS and DFS to those with initially resectable disease receiving the same regimen. ${ }^{33}$ Like many previous trials, this study found margin status to be the most powerful predictor of survival. This trial is interesting for having used gemcitabine as a radiation sensitizer, albeit at only $50 \mathrm{mg} / \mathrm{m}^{2}$ twice weekly, ${ }^{33}$ far less than the full dose of gemcitabine, $1,000 \mathrm{mg} / \mathrm{m}^{2}$ weekly, that has been shown to be of benefit in metastatic disease, ${ }^{4}$ and which would be hypothesized to better treat micrometastases.

\section{Role of gemcitabine in CRT}

Historically, 5-FU has been used as a radiation sensitizer in pancreatic cancer, even though it has been demonstrated to be inferior to gemcitabine for treating metastatic disease. ${ }^{4}$ The Massucco et $\mathrm{al}^{33}$ trial, described above demonstrated the possibility of secondary surgical resection after CRT, is one 


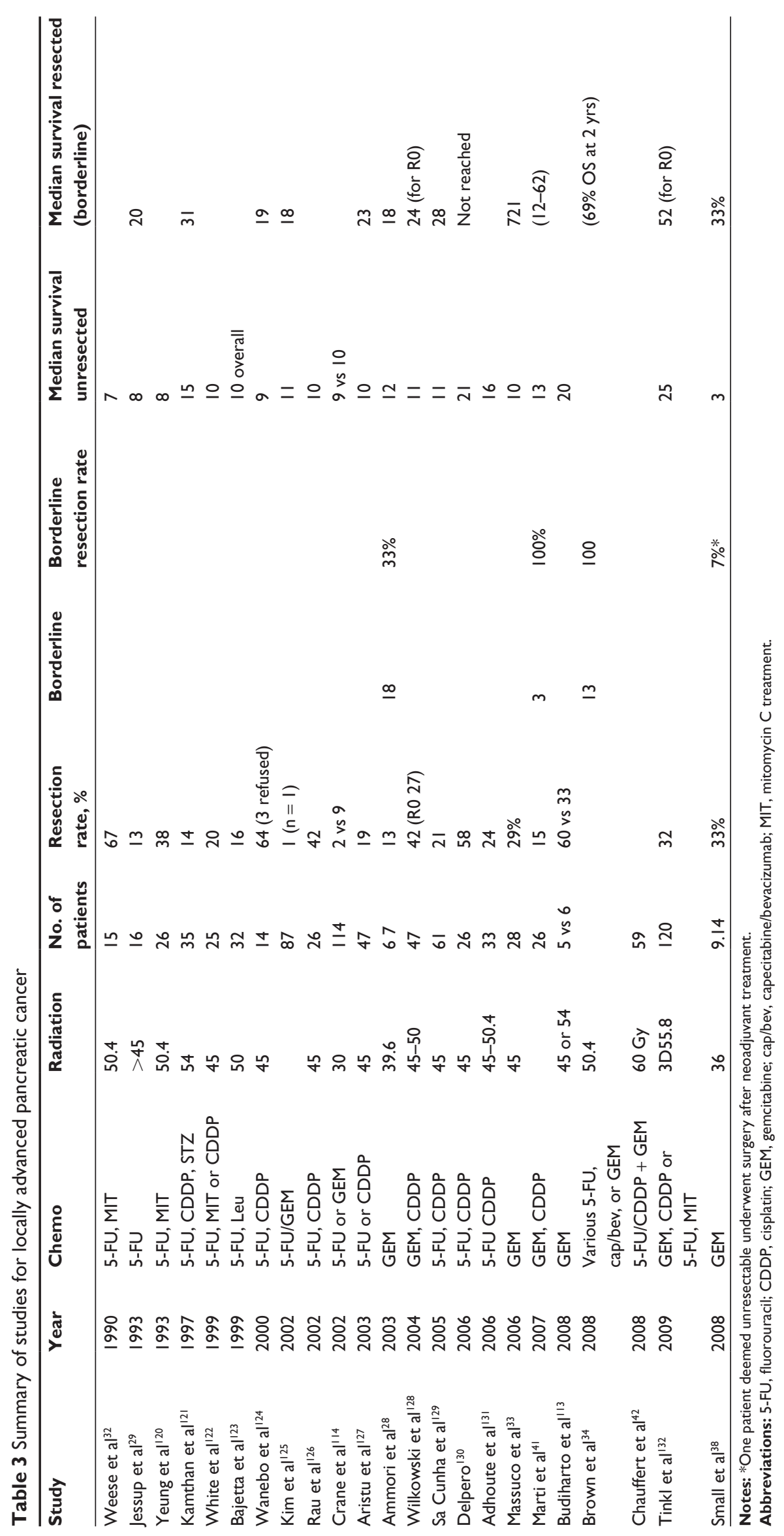


of a series of trials exploring the potential of gemcitabine as a radiation sensitizer. In the Munich Pancreas Trial, gemcitabine at a dose of $300 \mathrm{mg} / \mathrm{m}^{2}$ was give on days 1 , 15 , and 29 with 5-FU continuous infusion and concurrent radiation (45-50 Gy) in 32 patients with locally advanced unresectable pancreatic cancer. They demonstrated an overall response rate (RR) of 62.5\%. An impressive $37.5 \%$ of patients were found to be resectable after neoadjuvant treatment. ${ }^{35}$

An number of phase I and II trials have explored fulldose gemcitabine given in conjunction with varying doses of radiotherapy ${ }^{36,37}$ and have shown encouraging RRs, allowing in some cases for secondary surgery for previously unresectable disease. In a single-arm trial of 41 patients, Small et $\mathrm{al}^{38}$ have reported that full-dose gemcitabine with concurrent radiation (36 Gy) in nonmetastatic pancreatic cancer resulted in 3 of 9 cases of borderline resectable disease going on to secondary resection; 1 of 14 unresectable patients went on to resection. The 12-month survival rate in this study was 94\% (95\% confidence interval [CI]: 82\%-100\%) for primarily resectable disease, 76\% (95\% CI: 47\%-100\%) in secondary resection after neoadjuvant treatment, and 47\% (95\% CI: 19\%-75\%) for unresectable patients. Of 17 surgically resected patients, 16 showed negative margins at the time of resection, ${ }^{36}$ suggesting that the CRT may have contributed to local control; however, the large overlap in CIs for these results raises the necessity of a larger scale study to confirm the benefit of full-dose gemcitabine with concurrent radiation.

Because of the theoretical importance of full-dose gemcitabine for treating micrometastatic disease and for improving RRs, some researchers argue for the use of gemcitabine before and after 5-FU-based CRT in a sandwich regimen, explored in the Radiation Therapy Oncology Group (RTOG) 97-04 trial. 5 -FU was used as a radiosensitizer in both groups. Before and after CRT, patients received gemcitabine or 5-FU in a 1:1 ratio. OS was similar in both groups (18.8 months vs 16.9 months), but in subgroup analysis, patients with resectable pancreatic head mass had significant benefit on the gemcitabine arm (20.5 months vs 16.9 months, $P=0.033),{ }^{39}$ again suggesting the importance of gemcitabine in this disease.

\section{Comparing CRT to chemotherapy: neoadjuvant intent}

Although there have been no recent trials comparing adjuvant chemotherapy to CRT for resected pancreatic cancer, this comparison is being made in the setting of locally advanced pancreatic cancer.
Eastern Cooperative Oncology Group-4201(ECOG-4201) is the first study that directly compared gemcitabine in combination with radiation therapy vs gemcitabine alone in patients with locally advanced pancreatic cancer. In the radiation arm, gemcitabine was given at a dose of $600 \mathrm{mg} / \mathrm{m}^{2}$ weekly concurrent with radiation, and then followed by 5 cycles of full-dose gemcitabine. The concurrent CRT was found to be more myelosuppressive and was also associated with considerable gastrointestinal toxicity and fatigue. However, the addition of radiation therapy to gemcitabine significantly improved OS $(P=0.034)$ and tripled the survival rate at 24 months for patients with locally advanced pancreatic cancer. ${ }^{40}$

\section{Does more chemotherapy improve RRs to radiation?}

In a small trial, Marti et $\mathrm{al}^{41}$ found that adding cisplatin to gemcitabine with 45 Gy concurrent radiation was well tolerated and allowed some patients with locally advanced pancreatic cancer to go on to resection. However, this benefit has not been borne out in phase III trials. The French 20002001 Fédération Francophone de la Cancéologie Digestive/ Société Française de Radiothérapie Oncologie (FFCD/SFRO) study was a phase III trial comparing intensive induction CRT (60 Gy, infusional 5-FU and intermittent cisplatin) followed by maintenance gemcitabine with gemcitabine alone for locally advanced unresectable pancreatic cancer. This trial was a departure from the European approach of neoadjuvant chemotherapy alone. The intensive regimen unfortunately showed a significant decrease in OS from 13 to 8.6 months, ${ }^{42}$ possibly associated with toxicity of the aggressive chemotherapy. Although RR was not reported, there was similar tumor progression in both arms. The role of platinum agents in CRT for pancreatic cancer remains unsupported by evidence.

\section{Who is resectable? radiologic staging}

Although computed tomographic (CT) scans are the standard imaging modality at present, they are often unable to differentiate active pancreatic cancer from necrotic or fibrous tissue. ${ }^{43}$ Therefore, they are ineffective at identifying which tumors have been adequately downstaged to allow resection. Indeed, there are reports of complete pathologic response to neoadjuvant therapy not appreciated on preoperative scans. ${ }^{44}$ Thus, an important area of research is the development of advanced postprocessing techniques to increase the resolution of CT scanning for better restaging of disease, ${ }^{45}$ an important unmet need at present. An alternate modality for clinical assessment is 2-deoxy-2-[ $\left.{ }^{18} \mathrm{~F}\right]$ fluoro-D-glucose-positron 
emission tomographic scanning, which in 1 small study has been used to quantify response to neoadjuvant treatment. ${ }^{46}$ One approach to this dilemma is to err on the side of secondary surgery for curative intent, but this may increase the rate of futile surgery and subsequent complications.

\section{The future of neoadjuvant therapy in borderline unresectable and resectable diseases}

As the above definitions of resectability are incorporated into clinical trials and surgical technique and as criteria for assessment of margin status become standardized, the relative contributions of chemotherapy and radiation to the benefit neoadjuvant therapy will become more clear. ${ }^{14}$ Taken together, the trials conducted in locally advanced pancreatic cancer suggest that CRT is not only tolerable but also can downstage the disease, thus enabling secondary resection, possibly prolonging survival. The possibility of using fulldose gemcitabine as a radiation sensitizer is intriguing, but phase III trials have not yet been conducted with full-dose gemcitabine as a radiation sensitizer. Until such trials are available, a reasonable standard of care for locally advanced pancreatic cancer is the RTOG 97-04 sandwich approach with full-dose gemcitabine before and after CRT with 5-FU. ${ }^{39}$

\section{Metastatic disease: treating the patient not the disease}

Once pancreatic cancer becomes metastatic, it is uniformly fatal. At this point, the goal of treatment shifts away from curative attempts and toward prolonging survival while maintaining good quality of life. Chemotherapy is an important component of palliative care but must be deployed as part of a multidisciplinary approach to treat pain, minimizing weight loss, and manage declines in functional status.

\section{Pain control}

Pain control in advanced pancreas cancer needs to be aggressive and comprehensive. The appropriate initial line of attack is longacting narcotics supplemented by short-acting preparations for breakthrough pain. A key principle is to balance pain control against oversedation in order to maintain both comfortable and functional living. For patients who suffer from postprandial pain, multidisciplinary support is necessary. Postprandial pain may be alleviated by pancreatic enzyme replacement therapy (PERT), or celiac plexus block, both detailed below. Nutritional support is also important in staving off cachexia, which can interfere with pain management options like transdermal fentanyl.

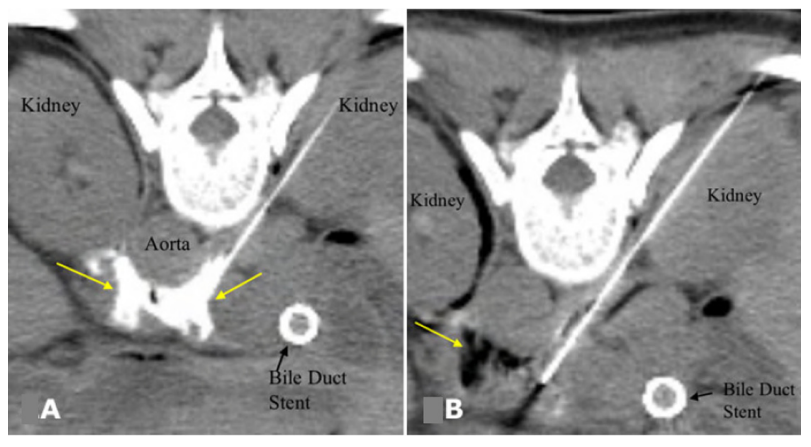

Figure 3 A) CT image after injection of a small volume of dilute contrast agent through both needles, confirming correct distribution of injected contrast around the celiac axis (arrows) prior to alcohol injection. B) After injection of alcohol, darkened region (arrow) shows its distribution in the vicinity of the celiac plexus. Copyright (c) 2007. Reproduced with permission from Arellano RS. Image-guided pain management, Part I: celiac plexus block for palliative pain relief. Radiology Rounds, Vol 5. Boston, MA: Massachusetts General Hospital; 2007.

For patients who have localized cancer-related pain, often described as band-like and radiating from the epigastrium, an important palliative option is neurolytic celiac plexus block (NCPB). In this procedure, an analgesic, such as lidocaine and an anti-inflammatory or a neurolytic agent, can be introduced to the celiac plexus. At some centers, this procedure may be done endoscopically with endoscopic ultrasound guidance, but it can also accomplished by fluoroscopic and CT guidance (see Figure 3). The approach may be made from either an anterior or an posterior approach based on anatomy and the patient's comfort. ${ }^{47}$ Celiac plexus block may also be applied intraoperatively on initial surgical exploration with $50 \%$ ethanol or $6 \%$ phenol under direct visualization during laparotomy. ${ }^{48}$ In a meta-analysis, partial or complete pain relief was achieved in $90 \%$ of patients via NCPB. ${ }^{49}$ NCPB can decrease the subsequent onset pain even in patients without preexisting pain at the time of surgery. ${ }^{50}$ Although the efficacy of this procedure is high, the duration or response is limited. As patients live longer, the efficacy of repeated NCPB diminishes, presumably due to disease metastasizing past the splanchnic bed, ${ }^{47}$ and systemic analgesics become necessary to control pain.

\section{PERT}

Patients with pancreatic cancer may suffer from symptoms of pancreatic enzyme deficiency and malabsorption. The deficiency stems from both disease-related obstruction of the pancreatic duct and destruction of normal pancreatic parenchyma, as well as unwanted consequences from interventional or surgical procedures. ${ }^{51}$ The rate of malabsorption can be $85 \%-90 \%$ in patients with pancreatic carcinoma, even in those who have not had surgery. ${ }^{52}$ Malabsorption can lead to vitamin and mineral 
deficiencies, particularly the fat-soluble vitamins A, D, E, and K. Symptoms of pancreatic enzyme deficiency include abdominal pain and distention, particularly postprandial, flatus, belching, diarrhea, steatorrhea, and weight loss.

To avoid symptoms and sequela of these deficiencies, it is important to provide pancreatic enzyme replacement therapy (PERT). A standard initial dose of replacement therapy is 50,000 IU of lipase with each meal. The dosage is then titrated to symptoms, leading eventually to a widely varying therapeutic range. PERT can be optimized with the addition of a proton-pump inhibitor, which increases intestinal $\mathrm{pH}$ and leads to decreased inactivation of prescribed PERT. ${ }^{53}$

\section{Nutritional status}

Pancreatic cancer is associated with cachexia, which is in and of itself a significant systemic symptom. Weight loss of $5 \%$ or more has been associated with an increased rate of metastatic disease, which renders surgical resection moot. ${ }^{54}$ It is not clear whether weight loss is causative since those with more tumor burden may lose more weight. Weight loss is, therefore, useful as a prognostic indicator ${ }^{55}$ and has even been considered an end point in major trials. ${ }^{4}$

Cachexia has important implications for symptom management. Because many cachectic patients with pancreatic cancer swallow poorly or have significant nausea and vomiting, transdermal fentanyl is an attractive treatment option. Unfortunately, cachexia has been demonstrated to decrease absorption of the narcotic due to lack of subcutaneous fat. ${ }^{56}$

For patients who have intractable nausea and vomiting on the basis of mechanical obstruction not amenable to endoscopic stenting, a gastric bypass surgery may be necessary to allow patients to continue to eat. A gastrojejunostomy with anastomosis between the jejunum and the anterior or posterior wall of the stomach can be performed to alleviate gastric outlet obstruction. ${ }^{57}$

\section{Hyperbilirubinemia}

Clearance of gemcitabine depends on a functioning liver. Thus, biliary tract obstruction due to tumor or complications of surgery, which may lead to hyperbilirubinemia as evidenced by jaundice, pruritus, and even direct neurotoxicity, ${ }^{58}$ can significantly delay optimal treatment. If the cancer is unresectable, biliary obstruction can often be relieved endoscopically by the placement of biliary stents. ${ }^{59}$ Stenting can decompress the biliary passages and relieve symptoms in the setting of pancreatic cancer, with $60 \%$ of patients experiencing complete resolution of pain and $25 \%$ of patients experiencing partial pain relief. ${ }^{59}$ However, stenting can also lead to many infectious complications. ${ }^{60}$ The main complication is stent occlusion, which accounts for the risk of cholangitis of approximately $7 \%$ in the setting of malignant biliary obstruction. ${ }^{61}$ Biliary stenting is also associated with up to a $10 \%$ postprocedure incidence of cholecystitis. ${ }^{62}$

To reduce the risk of stent occlusion and subsequent infectious complications, plastic stents, if used for malignant biliary obstruction, must be changed regularly. A more occlusion-resistant alternative to plastic stents is metal stents, which are, therefore, the intervention of choice in patients with malignant distal obstructive jaundice due to pancreatic carcinoma. ${ }^{63}$ Plastic stents should only be used in the palliative setting in patients with short predicted survival, who are not expected to require the patency benefits of metal stents. Historically, the surgical literature has reported postoperative infectious complications associated with preoperative stenting for patients undergoing pancreaticoduodenectomy. ${ }^{64-66}$ However, a Cochrane database review found no significant increased risk of infectious complications in this group, ${ }^{67}$ so there is no known rationale for avoiding this important palliative procedure.

In some cases, palliative surgery to bypass the biliary obstruction may be possible if endoscopic stenting is not feasible. Patency rates appear to be superior with surgical as opposed to endoscopic interventions, but at the cost of surgical morbidity. ${ }^{63}$ In addition, patients found to have unresectable disease at the time of laparotomy may benefit from a surgical biliary bypass with an hepaticojejunostomy, a procedure to anastomose the hepatic duct to the jejunum to relieve obstruction. ${ }^{57}$

\section{Chemotherapy for metastatic disease}

The primary intent of chemotherapy for metastatic pancreatic cancer is to relieve symptoms while prolonging survival. By causing tumor regression, chemotherapy may relieve the symptoms of biliary obstruction, reduce ascites, and contribute to resolving pain. Mallinson et $\mathrm{al}^{68}$ published the first randomized, controlled trial to demonstrate a survival benefit with systemic chemotherapy in 1980. Patients with unresectable disease (diagnosed at laparotomy) were treated with 5-FU, methotrexate, vincristine, and cyclophosphamide. Chemotherapy treatment was associated with a significant improvement in OS of 44 weeks compared with only 9 weeks with best supportive care (BSC). ${ }^{68}$ Several other combination regimens were then studied with promising results in phase II trials, but upon phase III evaluation, resulted in only modest 
improvements in progression-free survival (PFS) with no advantage in OS. ${ }^{69,70}$ This pattern of improvement in PFS without an OS benefit is common in subsequent trials in pancreatic cancer as well.

The next advancement in the treatment of metastatic disease was the establishment of single-agent gemcitabine as standard of care in the late 1990s. Burris et $\mathrm{al}^{4}$ conducted the pivotal trial. They compared weekly gemcitabine bolus of $1,000 \mathrm{mg} / \mathrm{m}^{2}$ to weekly 5 -FU bolus. Due to the palliative nature of chemotherapy at this stage, a clinical benefit response (CBR) scale, a composite score for pain, was used as the primary end point. A significant $23.8 \%$ of patients receiving gemcitabine had a CBR vs only $4.8 \%$ of patients in the 5-FU arm with a significant benefit in OS of 5.65 months vs 4.41 months, with few adverse events associated with the gemcitabine chemotherapy. ${ }^{4}$

Previous efforts to improve on chemotherapy were made using 5-FU as the basis for chemotherapy regimens, with little success; even a meta-analysis of 5-FU combination regimens showed no benefit of 5-FU-based combination therapy compared with 5 -FU alone. ${ }^{71}$ For the past several years, researchers have been duplicating this experience by adding different chemotherapies to a gemcitabine backbone, again with limited success.

\section{Efforts to improve upon gemcitabine: phase II promise does not predict success in phase III}

Although single-agent gemcitabine demonstrated its superiority over 5-FU in metastatic pancreatic cancer, the benefits were still modest. ${ }^{4}$ A number of trials have tried to improve the efficacy of gemcitabine by adding a number of other agents (see Table 4). Other efforts have been made to improve the efficacy of gemcitabine itself. In phase I studies, gemcitabine at a concentration of $20 \mu \mathrm{mol} / \mathrm{L}$ was found to maximize the rate of active gemcitabine triphosphate formation. This correlates to a fixed dose rate (FDR) of $10 \mathrm{mg} / \mathrm{m}^{2} / \mathrm{min}^{72}$ A phase II trial of FDR gemcitabine was also promising. OS on the FDR gemcitabine arm was associated with a significant improvement in OS of 8 months vs 5 months with standard dosing. ${ }^{73}$ Despite this encouraging data from a phase II trial, there was no benefit observed when FDR gemcitabine was evaluated as

Table 4 Phase III studies comparing addition to gemcitabine therapy

\begin{tabular}{|c|c|c|c|c|c|c|c|}
\hline Study & Chemo & Year & $\begin{array}{l}\text { No. of } \\
\text { patients }\end{array}$ & $\mathbf{R R}, \%$ & PFS, mo & OS, mo & $\begin{array}{l}\text { I-year } \\
\text { survival, \% }\end{array}$ \\
\hline \multirow[t]{2}{*}{ E2297 Berlin et al ${ }^{133}$} & GEM & 2002 & 322 & 5.6 & 2.2 & 5.4 & 14 \\
\hline & $\mathrm{GEM}+5-\mathrm{FU}$ & & & 6.9 & $3.4(P=0.022)$ & $6.7(P=0.09)$ & 20 \\
\hline \multirow[t]{2}{*}{ Reiss et al $\left.\right|^{134}$} & GEM & 2005 & 466 & & & 6.2 & 22 \\
\hline & GEM + 5-FU/leuk & & & & & $5.85(P=0.68)$ & $21(P=0.68)$ \\
\hline \multirow[t]{2}{*}{ Herrmann et $\mathrm{a}^{86}$} & GEM & 2007 & 319 & 7.8 & & 7.2 & 30 \\
\hline & GEM + cap & & & 10.0 & & $8.4(P=0.234)$ & 32 \\
\hline \multirow[t]{2}{*}{ Cunningham et $\mathrm{al}^{135}$} & GEM & 2005 & 533 & 7 & & 6.0 & 19 \\
\hline & GEM + cap & & & $14(P=0.008)$ & & $7.4(P=0.26)$ & 26 \\
\hline \multirow[t]{2}{*}{ Heinemann et $\mathrm{al}^{136}$} & GEM & 2006 & 190 & 8.2 & 3.1 & 6.0 & \\
\hline & GEM + cis & & & 10.2 & $5.3(P=0.053)$ & $7.5(P=0.15)$ & \\
\hline \multirow[t]{3}{*}{ E620I Poplin et al ${ }^{74}$} & GEM & 2009 & 824 & 6 & 2.6 & 4.9 & 16 \\
\hline & FDR GEM & & & $10(P=0.11)$ & $3.5(P=0.04)$ & $6.2(P=0.04)$ & 22 \\
\hline & GEM Ox & & & 9 & $2.7(P=0.1)$ & $5.7(P=0.22)$ & 21 \\
\hline GERCOR/GISCAD & GEM & 2005 & 313 & 17.3 & 3.7 & 7.1 & 27.8 \\
\hline Louvet et $\mathrm{al}^{76}$ & GEM Ox & & & 26.8 & $5.8(P=0.04)$ & $9.0(P=0.13)$ & $34.7(P=0.22)$ \\
\hline \multirow[t]{2}{*}{ Rocha Lima et al ${ }^{117}$} & GEM & 2004 & 342 & 4.4 & 3.0 & $6.6(P=0.789)$ & \\
\hline & GEM + iri & & & $16.1(P<0.001)$ & $3.5(P=0.352)$ & $6.3(P=0.789)$ & 20 \\
\hline \multirow[t]{2}{*}{ Strathopoulos et $\mathrm{al}^{137}$} & GEM & 2006 & 130 & 10 & 2.9 & 6.5 & 21.8 \\
\hline & GEM + iri & & & $15(P=0.387)$ & 2.8 & $6.4(P=0.97)$ & $24.3(P=0.666)$ \\
\hline \multirow[t]{2}{*}{ Abou-Alfa et al $\left.\right|^{138}$} & GEM & 2006 & 349 & 5.1 & 3.8 & 6.2 & 21 \\
\hline & GEM + exa & & & 6.8 & 3.7 & $6.7(P=0.52)$ & $23(P=0.52)$ \\
\hline \multirow[t]{2}{*}{ Reni et al ${ }^{139}$} & GEM & 2005 & 104 & 8.5 & 3.3 & & 21.3 \\
\hline & PEFG & & & 38.5 & $5.4(P=0.0033)$ & & $38.5(P=0.1 \mathrm{I})$ \\
\hline \multirow[t]{2}{*}{ Oettle et al ${ }^{140}$} & GEM & 2005 & 565 & 7.1 & 3.3 & 6.3 & 20.1 \\
\hline & GEM + pemetrexed & & & I4.8 $(P=0.004)$ & $3.9(P=0.11)$ & $6.2(P=0.85)$ & 21.4 \\
\hline
\end{tabular}

Abbreviations: RR, response rate; PFS, progression-free survival; OS, overall survival; GEM, gemcitabine; 5-FU, fluorouracil; Leuk, leukemia; cap, capecitabine; cis, cisplatin; FDR, fixed dose rate; GERCOR, French Multidisciplinary Clinical Research Group in Oncology; GISCAD, Italian Group for the Study of Gastrointestinal Tract Cancer; GEMOx, gemcitabine plus oxaliplatin; iri, irinotecan; exa, exatecan. 
one of the arms of ECOG-6201, a large phase III trial that also looked at the combination of gemcitabine plus oxaliplatin. ${ }^{74}$ Although FDR gemcitabine was associated with the longest OS (6.2 months), this outcome did not meet criteria for superiority, nor did the doublet of gemcitabine with the platinum, another area where multiple efforts have been made.

\section{Efforts adding a platinum}

There has been promising phase II data for adding a platinum to gemcitabine. For example, the French Multidisciplinary Clinical Research Group in Oncology (GERCOR) showed promising results with oxaliplatin combined with gemcitabine. ${ }^{75}$ When conducted in a phase III trial, however, despite improvements in RRs and PFS, OS was not statistically different. ${ }^{74,76}$ ECOG6201, a larger trial, was designed to test 2 promising approaches against standard single-agent gemcitabine in 832 patients with advanced pancreatic carcinoma. Disappointingly, the addition of oxaliplatin increased neither OS nor PFS significantly when compared with standard gemcitabine. ${ }^{74}$ Many authors consider this the definitive trial of platinum combinations, although interest in the combination continues.

Data presented at 2009 ASCO, including the Gruppo Italiano Pancreas-1(GIP-1) trial of gemcitabine combined with cisplatin vs gemcitabine alone in locally advanced and metastatic pancreatic cancer, failed to demonstrate any OS benefit or benefit in RR to adding the platinum. ${ }^{77}$

Many explanations for this consistent shortcoming among phase III trials of gemcitabine with a platinum drug have been proposed. Some postulate that this may be due to second-line therapy crossovers, or that combination therapy candidates need to be carefully selected for good performance status. ${ }^{76,78}$

\section{Do meta-analyses shed light on the role of a platinum analog?}

In the metastatic setting, till date, the only first-line phase III combination chemotherapy trial to show benefit over singleagent gemcitabine was the addition of erlotinib. ${ }^{79}$ Despite promising results with the addition of a platinum agent in the phase II setting, when conducted in a phase III trial, despite improvements in RRs and PFS, OS is not statistically different. ${ }^{74,76} \mathrm{~A}$ number of meta-analyses have been undertaken in an effort to tease out the benefit of combination therapy. ${ }^{80}$ Heinemann et $\mathrm{al}^{81}$ pooled the results of the GERCOR/Italian Group for the Study of Gastrointestinal Tract Cancer (GISCAD) intergroup study comparing gemcitabine plus oxaliplatin to gemcitabine and a German multicenter trial comparing gemcitabine plus cisplatin vs gemcitabine and concluded that a platinum analog significantly improved PFS and OS as compared with single-agent gemcitabine in advanced pancreatic cancer in patients with a good performance status, ${ }^{81}$ similar to other pooled analyses. ${ }^{80}$ These meta-analyses raise interesting questions, but are not comprehensive enough to dictate standard of care. For example, 2 phase III trials not included in the Heinemann analysis did not show an advantage when cisplatin was combined with gemcitabine. ${ }^{82,83}$ Also discouragingly, a different meta-analyses showed no significant improvement in survival when using cisplatin in combination with gemcitabine. ${ }^{84}$

\section{Efforts adding capecitabine}

Another notable example of the difference in results between phase II and III trials in pancreatic cancer are trials of capecitabine, which shows activity comparable with gemcitabine in phase II trials. ${ }^{85}$ In the phase III setting, however (see Table 4), there was no statistically significant difference between the gemcitabine plus capecitabine arm compared with the gemcitabine arm. ${ }^{86}$ Interestingly, in a post hoc analysis, patients in this study with a Karnofsky Performance score (PS) of $>90$ had a significantly improved OS of 10.1 months vs 7.4 months, suggesting again that the subset of patients with excellent PS may benefit from combination therapy. ${ }^{80}$ The positive phase II results may stem in part from better PS in phase II trial participants than in larger trials.

\section{Targeting the EGFR pathway: statistical significance does not mean clinical relevance}

Of all molecularly targeted agents studied in phase III trials, only erlotinib, targeting the human epidermal growth factor receptor 1 (HER-1/EGFR), has demonstrated statistical significant improvement over gemcitabine alone. However, the clinical benefit of this addition is uninspiring. In a phase III randomized trial, erlotinib with gemcitabine was associated with statistically significant 1-year survival advantage of $23 \%$ vs $17 \%$; PFS of 3.75 months vs 3.55 months; and OS of 6.24 months vs 5.91 months. This was approved by the US Food and Drug Administration (FDA) due to all of these end points achieving statistical significance, a feat that could not be demonstrated in cytotoxic agents above. Clinically, however, the addition of erlotinib manifests a median benefit of only 0.33 months, or about 10 days. ${ }^{79}$

The most common toxicity of anti-EGFR agents is an acne-like rash, which may vary in severity. Interestingly, in a review of both cetuximab and erlotinib in a variety of solid tumors, multiple studies demonstrate a correlation between 
efficacy and severity of the acneiform rash. In a phase II study of cetuximab and gemcitabine for pancreatic cancer, not only the presence of the rash but also the severity of it was associated with longer survival. ${ }^{87}$

\section{Second-line therapy: an area of great need}

Currently, there is a lack of proven therapy in the secondline, a great unmet need as most patients do not have a good response to first-line therapy. The only established secondline regimen after failure of first-line gemcitabine in the metastatic setting is 5-FU with oxaliplatin. In the CONKO003 trial, a phase III trial of oxaliplatin and 5-FU with folinic acid vs BSC, patients who received second-line therapy were noted to have an OS of 40 weeks compared with 34.4 weeks after initiation of second-line chemotherapy $(P=0.0312) .{ }^{88}$ It is notable that in this study, after 46 of 165 patients were randomized, the BSC arm was closed due to participating centers deciding that BSC alone was no longer acceptable. This benefit, although statistically significant, is small and points to the dire need for more investigation.

\section{Directions of current research}

A number of genetic alterations have been shown to occur in pancreatic cancer. Commonly mutated genes include the oncogenes K-ras (75\%-100\%), HER2/neu (about 65\%), p16 $6^{\text {Ink } 4 a}$ $(>90 \%)$, notch1, Akt-2, and COX-2 and also the tumor suppressor genes p 53 (45\%-75\%), DPC4 (approximately 50\%), FHIT (70\%), and BRCA2. Despite this diversity of mutations, none of these genes is currently being targeted in clinical practice. ${ }^{89}$ The promise of targeted therapies nevertheless continue to hold great interest in this disease, and other approaches, such as concentrating the role of the tumor stroma, overcoming resistance mechanisms to chemotherapy, and recruiting immune defenses, show early promise and are highlighted below.

\section{Targeted therapies: efforts to improve on the best available}

The tyrosine kinase inhibitor erlotinib is the first and only molecularly targeted therapy approved by the FDA for firstline treatment of advanced pancreatic cancer in combination with gemcitabine. ${ }^{79}$ As this is currently FDA approved, it is discussed above. Several investigators have sought to build upon the benefit of erlotinib. A phase I trial was conducted of erlotinib CRT with gemcitabine followed by maintenance erlotinib for locally advanced pancreatic cancer. ${ }^{90}$ A retrospective study of single-agent erlotinib as second-line therapy showed no observed responses. ${ }^{91}$ Second-line erlotinib with capecitabine in gemcitabine refractory pancreatic cancer showed a modest median survival time of 6.5 months and a RR of $10 \% .^{92}$

\section{Cetuximab: limited activity}

A monoclonal antibody against HER1/EGFR, cetuximab, has been demonstrated to have activity in pancreatic cancer when combined with gemcitabine.$^{87}$ This combination is being tested in the phase III setting, but unfortunately, preliminary reports suggest that this trial will likely fail to significantly improve OS time $^{93}$ (see Table 5). Nongemcitabine-based first-line therapy with cetuximab has also been studied. An ECOG phase II trial with randomization between irinotecan and docetaxel vs irinotecan and docetaxel plus cetuximab demonstrated modest improvements in clinical response with an OS time of 7.4 months with cetuximab vs 6.5 months without. ${ }^{94}$

Table 5 Phase III trials of molecularly targeted agents for advanced and metastatic pancreatic cancer

\begin{tabular}{|c|c|c|c|c|c|c|c|}
\hline Author & Chemo & Year & $\begin{array}{l}\text { No. of } \\
\text { patients }\end{array}$ & RR, \% & PFS (mo) & OS (mo) & $\begin{array}{l}\text { I-year } \\
\text { survival (\%) }\end{array}$ \\
\hline \multirow[t]{2}{*}{ Bramhall et al ${ }^{141}$} & Marimastat & 2001 & 414 & 3 & 2.9 & 4 & $14-20$ \\
\hline & GEM & & & 26 & $4.9(P=0.0001)$ & $5.6(P=0.19)$ & 19 \\
\hline \multirow[t]{2}{*}{ Bramhall et al ${ }^{142}$} & GEM & 2002 & 239 & 16 & 3.2 & 5.5 & 17 \\
\hline & GEM + marimastat & & & 11 & $3.1(P=0.68)$ & $5.4(P=0.95)$ & 18 \\
\hline \multirow[t]{2}{*}{ Moore et al ${ }^{143}$} & Talomastat & 2003 & 277 & $\mathrm{I}$ & 1.68 & 3.74 & 10 \\
\hline & GEM & & & 5 & $3.5(P<0.001)$ & 6.59 & 25 \\
\hline \multirow[t]{2}{*}{ Van Cutsem et al ${ }^{144}$} & GEM & 2007 & 688 & 8 & $3.6(P=0.72)$ & 6.1 & 24 \\
\hline & GEM + tafarnib & & & 6 & 3.7 & $6.4(P=0.75)$ & 27 \\
\hline \multirow[t]{2}{*}{ Philip ${ }^{93}$ S0205 } & Cetuximab & 2007 & & 7 & 3.5 & 6.5 & \\
\hline & & & & 7 & $3(P=0.058)$ & $6.0(P=0.14)$ & \\
\hline Kindler et $\mathrm{al}^{96}$ & Bevacizumab & 2007 & & II & 4.7 & 5.8 & \\
\hline \multicolumn{8}{|l|}{ CALGB 8030} \\
\hline & & & & 10 & $4.9(P=0.99)$ & $6.1(P=0.78)$ & \\
\hline
\end{tabular}

Abbreviations: RR, response rate; PFS, progression-free survival; OS, overall survival; GEM, gemcitabine. 


\section{Targeting the vascular epithelial growth factor may be inactive in pancreatic cancer}

The vascular epithelial growth factor (VEGF) and its receptors are attractive targets for antineoplastic therapy, particularly as they have a theoretical benefit in improving chemotherapy delivery to tumor. In a phase II trial, the antiVEGF monoclonal antibody bevacizumab demonstrated activity in advanced pancreatic cancer with a RR of $21 \%$ and a median survival time of 8.8 months ${ }^{95}$ Yet again, these phase II results were not borne out in the phase III setting. The Cancer and Leukemia Group B (CALGB) 8030, a phase III, trial showed disappointing results for OS and was terminated early ${ }^{96}$ Sorafenib, a multikinase inhibitor against VEGFR, platelet-derived growth factor receptor, Kit, and Flt-3, was demonstrated to have no activity in combination with gemcitabine in phase II trial, ${ }^{97}$ although it is being investigated in the second-line setting. ${ }^{98}$

\section{Secreted protein acid rich in cysteine (SPARC): the stroma as the target}

The role of the pancreatic cancer stroma is an area of active research regarding the pathogenesis of the disease and its vigorous resistance to chemotherapy. ${ }^{99,100}$ Pancreatic adenocarcinoma is characterized by a strong desmoplastic reaction, which may promote the malignant phenotype. ${ }^{101,102}$ Pancreatic stellate cells (PSC) have been shown to produce substances that aid in the invasion of pancreatic cancer. The level of paracrine secreted protein acidic and rich in cysteine (SPARC) from PSC has been demonstrated to be inversely proportional to survival. ${ }^{101}$ This makes SPARC in the PSCs an attractive adjunct target. Nab-paclitaxel uses endogenous albumin pathways via binding of the albumin to SPARC. In a phase II trial as first-line therapy in metastatic pancreatic cancer, nabpaclitaxel and gemcitabine were given on days 1,8 , and 15 of a 28-day cycle. One patient had a complete response to therapy, 12 patients (24\%) had partial response (PR), and 20 patients (41\%) had stable disease (SD). Median PFS increased from 4.8 months for SPARC-negative patients to 6.2 months for SPARC-positive patients. ${ }^{103} \mathrm{In}$ a proof-of-principle parallel study in mouse xenografts, researchers demonstrated that nab-paclitaxel depleted the stroma surrounding pancreatic tumors and thus was able to facilitate delivery of gemcitabine more effectively. Those treated with the combination had a gemcitabine concentration in tumors that was 3.7 -fold higher than that seen with gemcitabine alone. ${ }^{104}$ SPARC is, therefore, emerging as an important biomarker of response to nab-paclitaxel chemotherapy in this disease.

\section{CP-4I 26: gemcitabine evolved}

The human equilibrative nucleoside transporter 1 and human concentrative nucleoside transporter 1 and 3 are responsible for gemcitabine uptake into tumor cells. Lack of these transporters denotes a poorer prognosis with adjuvant treatment and predicts for resistance to therapy. ${ }^{105}$ A promising new nucleoside analog that bypasses this mechanism has shown some benefit in refractory solid tumors in phase I trials, including stabilization of disease in some patients with pancreatic cancer. Though a derivative of gemcitabine, CP-4126 does not require nucleoside transporters. ${ }^{106}$ This agent is currently entering phase II trials.

\section{Vaccine trials: new techniques hold promise}

In 2002, dendritic cells derived from peripheral blood monocytes were transfected with human tumor antigen mucin (MUC1) to be used as a vaccine for advanced breast, pancreatic, or papillary cancer. In this phase I trial, it was demonstrated that immune responses could be induced in 4 of 10 patients, but only 1 patient with a response had observed benefit. Despite lack of efficacy, treatment was regarded as safe. ${ }^{107}$ The same year, a phase I/II trial using d11520, a gene-deleted replicationselective adenovirus that targets malignant cells, was delivered by endoscopic ultrasound in combination with gemcitabine in locally advanced pancreatic cancer. Though this was also deemed safe with only small elevations of pancreatic enzymes and no pancreatitis, the effect was modest with $20 \% \mathrm{RR}$ and another $38 \% \mathrm{SD} .{ }^{108}$ One complete remission of liver metastasis of pancreatic cancer refractory to gemcitabine was reported. ${ }^{109}$ Encouragingly, a recent a phase I trial with peptide vaccine for VEGFR2 using the epitope peptide VGFR2-169 in combination of gemcitabine shows promising results in advanced pancreatic cancer. The control rate was $67 \%$ with a OS of 8.7 months with 1 PR and 11 patients (61\%) with SD. ${ }^{110}$ Clearly, this is an evolving field in which more study is needed, and trials are ongoing, including a trial of endoscopically-guided intratumoral injections, as intratumoral injections have been demonstrated to generate an enhanced systemic tumor-specific immune response in a preclinical model. ${ }^{111}$ 


\section{Summary}

Despite improved surgical outcomes and advances in chemotherapy and radiation therapy, overall 5-year survival of pancreatic cancer is approximately $5 \% .{ }^{112}$ Although complete surgical resection offers the only chance for long-term survival, the majority of patients who undergo surgery with curative intent will eventually succumb to the disease. ${ }^{3}$

A multidisciplinary approach with CRT holds the promise of downstaging a locally advanced cancer and sterilizing the perivascular neoplastic tissue and even distant micrometastatic disease and results in a survival advantage as compared with unresected patients. Although the optimal regimen has not been identified, there is strong phase II evidence that full-dose gemcitabine can be tolerated in combination with adequate radiation, and this dose is theoretically most likely to address micrometastatic disease outside of the radiation field. There appears to be a trend toward higher RRs with gemcitabine-based CRT that must be confirmed in multicenter trials. ${ }^{38,113-115}$

In metastatic disease, chemotherapy is an important component of a multidisciplinary approach to palliative care, which must be supported by pain management and nutrition. Gemcitabine has been considered the standard treatment for patients with advanced pancreatic cancer ever since Burris et $\mathrm{al}^{4}$ demonstrated a modest, yet statistically significant, improvement in OS and a significant clinical benefit for gemcitabine chemotherapy compared with 5-FU. However, single-agent gemcitabine in multiple trials consistently only achieves median OS figures of approximately 6 months, a finding that clearly indicates the need for the development of new treatment strategies. ${ }^{116}$ Phase I and phase II trials of a variety of gemcitabine-based combinations have demonstrated promising activity. Invariably, when these have been evaluated in randomized phase III trials compared with single-agent gemcitabine, the results have been disappointing.

The conclusive results of ECOG-6201 establish that adding oxaliplatin to gemcitabine is not an appropriate standard of care for patients with advanced pancreatic cancer. ${ }^{74}$ Some meta-analyses, however, have found that overall RRs were significantly improved by gemcitabine-based combination therapy with a platinum ${ }^{80,81}$ or fluoropyrimidine ${ }^{80}$ particularly in patients with good performance status. Other combination therapies have shown promise in improving the RR, eg, a phase III study of the combination of irinotecan with gemcitabine vs gemcitabine in patients with advanced or metastatic pancreatic cancer, with a primary end point of survival, a statistically significant improvement in RR was found although the primary end point of survival was not reached. ${ }^{117}$ Similarly, the GERCOR trial demonstrated an improved RR with the addition of oxaliplatin to gemcitabine ${ }^{76}$ a benefit not seen in the larger ECOG trial. ${ }^{74}$

The possibility of improved RR with combination therapy, however, does raise the question: would combination therapy be worth examining in the neoadjuvant setting, where RR dictates the possibility of future resection?

In future trials, it will be important to stratify patients by modern criteria for resectability to elucidate the benefit of our therapies. Most neoadjuvant trials have grouped together: patients with borderline resectable, resectable, and borderline unresectable disease. Most chemotherapy trials have treated as one group: patients with unresectable locally advanced disease, recurrent disease, and metastatic disease. There is increasing evidence that the prognosis is different in these stages of disease, ${ }^{118}$ although micrometastasis may already present in most patients. We are doing the research process and our patients a disservice if we do not stratify the patients in our trials by modern criteria. Trials of innovative technology, such as vaccines, should pay particular attention to the characteristics of patients' disease.

Some of the most interesting current research seeks to differentiate which patients will respond to therapy. As evidenced by the relatively low RRs with gemcitabine, better biological markers to help predict response are urgently needed if we are to make progress in this disease.

\section{Acknowledgments and disclosure}

The authors reports no conflicts of interest in this work. The authors also thank Dana Herrigel, MD, Maureen Huhmann, DCn, RD, CS, Imran Khan, MD, and Samuel SH Wang, $\mathrm{PhD}$.

\section{References}

1. Janes RH Jr, Niederhuber JE, Chmiel JS, et al. National patterns of care for pancreatic cancer. Results of a survey by the Commission on Cancer. Ann Surg. 1996;223(3):261-272.

2. Calle EE, Rodriguez C, Walker-Thurmond K, Thun MJ. Overweight, obesity, and mortality from cancer in a prospectively studied cohort of U.S. adults. $N$ Engl J Med. 2003;348(17):1625-1638.

3. Shaib Y, Davila J, Naumann C, El-Serag H. The impact of curative intent surgery on the survival of pancreatic cancer patients: a U.S. Populationbased study. Am J Gastroenterol. 2007;102(7):1377-1382.

4. Burris HA III, Moore MJ, Andersen J, et al. Improvements in survival and clinical benefit with gemcitabine as first-line therapy for patients with advanced pancreas cancer: a randomized trial. J Clin Oncol. 1997;15(6):2403-2413

5. Kastrinos F, Mukherjee B, Tayob N, et al. Risk of pancreatic cancer in families with Lynch syndrome. JAMA. 2009;302(16):1790-1795.

6. Ferrone CR, Levine DA, Tang LH, et al. BRCA germline mutations in Jewish patients with pancreatic adenocarcinoma. J Clin Oncol. 2009;27(3): 433-438. 
7. Bao Y, Michaud DS. Physical activity and pancreatic cancer risk: a systematic review. Cancer Epidemiol Biomarkers Prev. 2008; 17(10):2671-2682.

8. Michaud DS, Giovannucci E, Willett WC, Colditz GA, Stampfer MJ, Fuchs CS. Physical activity, obesity, height, and the risk of pancreatic cancer. JAMA. 2001;286(8):921-929.

9. Li D, Morris JS, Liu J, et al. Body mass index and risk, age of onset, and survival in patients with pancreatic cancer. JAMA. 2009;301(24):2553-2562.

10. Gumbs AA. Obesity, pancreatitis, and pancreatic cancer. Obes Surg. 2008;18(9):1183-1187.

11. Smeenk HG, Tran TC, Erdmann J, van Eijck CH, Jeekel J. Survival after surgical management of pancreatic adenocarcinoma: does curative and radical surgery truly exist? Langenbecks Arch Surg. 2005; 390(2):94-103.

12. Mu DQ, Peng SY, Wang GF. Risk factors influencing recurrence following resection of pancreatic head cancer. World J Gastroenterol. 2004;10(6):906-909.

13. Shibata K, Matsumoto T, Yada K, Sasaki A, Ohta M, Kitano S. Factors predicting recurrence after resection of pancreatic ductal carcinoma. Pancreas. 2005;31(1):69-73.

14. Abrams RA, Lowy AM, O'Reilly EM, Wolff RA, Picozzi VJ, Pisters PW. Combined modality treatment of resectable and borderline resectable pancreas cancer: expert consensus statement. Ann Surg Oncol. 2009;16(7):1751-1756.

15. Kalser MH, Ellenberg SS. Pancreatic cancer. Adjuvant combined radiation and chemotherapy following curative resection. Arch Surg. 1985;120(8):899-903.

16. Klinkenbij1 JH, Jeekel J, Sahmoud T, et al. Adjuvant radiotherapy and 5-fluorouracil after curative resection of cancer of the pancreas and periampullary region: phase III trial of the EORTC gastrointestinal tract cancer cooperative group. Ann Surg. 1999;230(6): 776-782.

17. Garofalo MC, Regine WF, Tan MT. On statistical reanalysis, the EORTC trial is a positive trial for adjuvant chemoradiation in pancreatic cancer. Ann Surg. 2006;244(2):332-333.

18. Neoptolemos JP, Stocken DD, Friess H, et al; for the European Study Group for Pancreatic Cancer. A randomized trial of chemoradiotherapy and chemotherapy after resection of pancreatic cancer. $N$ Engl J Med. 2004;350(12):1200-1210

19. Choti M. Adjuvant therapy for pancreatic cancer - the debate continues. N Engl J Med. 2004;350(12):1249-1251.

20. Crane CH, Ben-Josef E, Small W Jr. Chemotherapy for pancreatic cancer. $N$ Engl J Med. 2004;350(26):2713-2715.

21. Kosuge T, Kiuchi T, Mukai K, Kakizoe T; for the Japanese Study Group of Adjuvant Therapy for Pancreatic Cancer (JSAP). A multicenter randomized controlled trial to evaluate the effect of adjuvant cisplatin and 5-fluorouracil therapy after curative resection in cases of pancreatic cancer. Jpn J Clin Oncol. 2006;36(3):159-165.

22. Oettle H, Post S, Neuhaus P, et al. Adjuvant chemotherapy with gemcitabine vs observation in patients undergoing curative-intent resection of pancreatic cancer: a randomized controlled trial. JAMA. 2007;297(3):267-277.

23. Ueno H, Kosuge T, Matsuyama Y, et al. A randomised phase III trial comparing gemcitabine with surgery-only in patients with resected pancreatic cancer: Japanese Study Group of Adjuvant Therapy for Pancreatic Cancer. Br J Cancer. 2009;101(6):908-915.

24. Neoptolemos J, Büchler M, Stocken DD, et al. ESPAC-3(v2): A multicenter, international, open-label, randomized, controlled phase III trial of adjuvant 5-fluorouracil/folinic acid (5-FU/FA) versus gemcitabine (GEM) in patients with resected pancreatic ductal adenocarcinoma. ASCO Annual Meeting. JClin Oncol. 2009;27 Suppl 18. Abstract LBA4505.

25. Varadhachary GR, Tamm EP, Abbruzzese JL, et al. Borderline resectable pancreatic cancer: definitions, management, and role of preoperative therapy. Ann Surg Oncol. 2006;13(8):1035-1046.

26. Ujiki MB, Talamonti MS. Guidelines for the surgical management of pancreatic adenocarcinoma. Semin Oncol. 2007;34(4):311-320.
27. White RR, Hurwitz HI, Morse MA, et al. Neoadjuvant chemoradiation for localized adenocarcinoma of the pancreas. Ann Surg Oncol. 2001; $8(10): 758-765$.

28. Ammori JB, Colletti LM, Zalupski MM, et al. Surgical resection following radiation therapy with concurrent gemcitabine in patients with previously unresectable adenocarcinoma of the pancreas. $J$ Gastrointest Surg. 2003;7(6):766-772.

29. Jessup JM, Steele G Jr, Mayer RJ, et al. Neoadjuvant therapy for unresectable pancreatic adenocarcinoma. Arch Surg. 1993;128(5):559-564.

30. Pilepich MV, Miller HH. Preoperative irradiation in carcinoma of the pancreas. Cancer Biol Ther. 1980;46(9):1945-1949.

31. Brunner TB, Grabenbauer GG, Baum U, Hohenberger W, Sauer R. Adjuvant and neoadjuvant radiochemotherapy in ductal pancreatic carcinoma. Strahlenther Onkol. 2000;176(6):265-273.

32. Weese JL, Nussbaum ML, Paul AR, et al. Increased resectability of locally advanced pancreatic and periampullary carcinoma with neoadjuvant chemoradiotherapy. Int J Pancreatol. 1990;7(1-3):177-185.

33. Massucco P, Capussotti L, Magnino A, et al. Pancreatic resections after chemoradiotherapy for locally advanced ductal adenocarcinoma: analysis of perioperative outcome and survival. Ann Surg Oncol. 2006; 13(9):1201-1208.

34. Brown KM, Siripurapu V, Davidson M, et al. Chemoradiation followed by chemotherapy before resection for borderline pancreatic adenocarcinoma. Am J Surg. 2008;195(3):318-321.

35. Wilkowski R, Thoma M, Bruns C, Wagner A, Heinemann V. Chemoradiotherapy with gemcitabine and continuous $5-\mathrm{FU}$ in patients with primary inoperable pancreatic cancer. JOP. 2006;7(4):349-360.

36. Talamonti MS, Small W Jr, Mulcahy MF, et al. A multi-institutional phase II trial of preoperative full-dose gemcitabine and concurrent radiation for patients with potentially resectable pancreatic carcinoma. Ann Surg Oncol. 2006;13(2):150-158.

37. Ioka T, Tanaka S, Nakaizumi A, Nishiyama K. A phase I trial of chemoradiation therapy with concurrent full dose gemcitabine for unresectable locally advanced pancreatic adenocarcinoma. J Clin Oncol. 2005;23(165):4209.

38. Small W Jr BJ, Freedman GM, et al. Full-dose gemcitabine with concurrent radiation therapy in patients with nonmetastatic pancreatic cancer: a multicenter phase II trial. J Clin Oncol. 2008;26(6): 942-947.

39. Regine WF, Winter KA, Abrams RA, et al. Fluorouracil vs gemcitabine chemotherapy before and after fluorouracil-based chemoradiation following resection of pancreatic adenocarcinoma: a randomized controlled trial. JAMA. 2008;299(9):1019-1026.

40. Loehrer PJ, Powell ME, Cardenes HR, et al. A randomized phase III study of gemcitabine in combination with radiation therapy versus gemcitabine alone in patients with localized, unresectable pancreatic cancer: E4201. J Clin Oncol. 2008;26 Suppl 20. Abstract 4506.

41. Marti JL, Hochester HS, Hiotis SP, Donahue B, Ryan T, Newman E. Phase I/II trial of induction chemotherapy followed by concurrent chemoradiotherapy and surgery for locoregionally advanced pancreatic cancer. Ann Surg Oncol. 2008;15(12):3521-3531.

42. Chauffert B, Mornex F, Bonnetain F, et al. Phase III trial comparing intensive induction chemoradiotherapy ( $60 \mathrm{~Gy}$, infusional 5-FU and intermittent cisplatin) followed by maintenance gemcitabine with gemcitabine alone for locally advanced unresectable pancreatic cancer. Definitive results of the 2000-01 FFCD/SFRO study. Ann Oncol. 2008;19(9): $1592-1599$.

43. White RR, Xie HB, Gottfried MR, et al. Significance of histological response to preoperative chemoradiotherapy for pancreatic cancer. Ann Surg Oncol. 2005;12(3):214-221.

44. Peddu P, Quaglia A, Kane PA, Karani JB. Role of imaging in the management of pancreatic mass. Crit Rev Oncol Hematol. 2009;70(1):12-23.

45. Tamm E, Charnsangavej C, Szklaruk J. Advanced 3-D imaging for the evaluation of pancreatic cancer with multidetector CT. Int J Gastrointest Cancer. 2001;30(1-2):65-71. 
46. Maisey NR, Webb A, Flux GD, et al. FDG-PET in the prediction of survival of patients with cancer of the pancreas: a pilot study. $\mathrm{Br} J$ Cancer. 2000;83(3):287-293.

47. Mercadante S, Nicosia F. Celiac plexus block: a reappraisal. Reg Anesth Pain Med. 1998;23(1):37-48.

48. Sakorafas GH, Tsiotou AG, Sarr MG. Intraoperative celiac plexus block in the surgical palliation for unresectable pancreatic cancer. Eur J Surg Oncol. 1999;25(4):427-431.

49. Eisenberg E, Carr DB, Chalmers TC. Neurolytic celiac plexus block for treatment of cancer pain: A meta-analysis. Anesth Analg. 1995;8(2):290-295.

50. Lillemoe KD, Cameron JL, Kaufman HS. Chemical splanchnicectomy in patients with unresectable pancreatic cancer: a prospective randomized trial. Ann Surg. 1993;217(5):447-455.

51. Matsumoto J, Traverso LW. Exocrine function following the whipple operation as assessed by stool elastase. J Gastrointest Surg. 2006;10(9):1225-1229.

52. Perez MM, Newcomer AD, Moertel CG, Go VL, Dimagno EP. Assessment of weight loss, food intake, fat metabolism, malabsorption, and treatment of pancreatic insufficiency in pancreatic cancer. Cancer. 1983;52(2):346-352.

53. Bruno MJ, Haverkort EB, Tijssen GP. Placebo controlled trial of enteric coated pancreatin microsphere treatment in patients with unresectable cancer of the pancreatic head region. Gut. 1998;42:92-96.

54. Bachmann J, Ketterer K, Marsch C, et al. Pancreatic cancerrelated cachexia: influence on metabolism and correlation to weight loss and pulmonary function. BMC Cancer. 2009;28(9):255.

55. Robinson DW Jr, Eisenberg DF, Cella D, Zhao N, de Boer C, DeWitte M. The prognostic significance of patient-reported outcomes in pancreatic cancer cachexia. J Support Oncol. 2008;6(6):283-290.

56. Heiskanen T, Matzke S, Haakana S, Gergov M, Vuori E, Kalso E. Transdermal fentanyl in cachectic cancer patients. Pain. 2009;144(1-2):218-222.

57. Mann CD, Thomasset SC, Johnson NA, et al. Combined biliary and gastric bypass procedures as effective palliation for unresectable malignant disease. ANZ J Surg. 2009;79(6):471-475.

58. Can B, Saray A, Caglikulekçi M, Saran Y. Effects of obstructive jaundice on the peripheral nerve: an ultrastructural study in rats. Eur Surg Res. 2004;36(4):226-233.

59. Costamagna G, Pandolfi M. Endoscopic stenting for biliary and pancreatic malignancies. J Clin Gastroenterol. 2004;38:59-67.

60. Ballinger AB, McHugh M, Catnach SM. Symptom relief and quality of life after stenting for malignant bile duct obstruction. Gut. 1994;35: 467-470.

61. Tibble JA, Cairns SR. Role of endoscopic endoprostheses in proximal malignant biliary obstruction. J Hepatobiliary Pancreat Surg. 2001;8(2):118-123.

62. Suk KT, Kim HS, Kim JW, et al. Risk factors for cholecystitis after metal stent placement in malignant biliary obstruction. Gastrointest Endosc. 2006;64(4):522-529.

63. Moss AC, Morris E, Mac Mathuna P. Palliative biliary stents for obstructing pancreatic carcinoma. Cochrane Database Syst Rev. 2006;(2):CD004200.

64. Povoski SP, Karpeh MS Jr, Conlon KC, Blumgart LH, Brennan MF. Association of preoperative biliary drainage with postoperative outcome following pancreaticoduodenectomy. Ann Surg. 1999;230(2):131-142.

65. Sohn TA, Yeo CJ, Cameron JL, Pitt HA, Lillemoe KD. Do preoperative biliary stents increase postpancreaticoduodenectomy complications? J Gastrointest Surg. 2000;4(3):258-267; discussion 267-258.

66. Hochwald SN, Burke EC, Jarnagin WR, Fong Y, Blumgart LH. Association of preoperative biliary stenting with increased postoperative infectious complications in proximal cholangiocarcinoma. Arch Surg. 1999;134(3):261-266.

67. Mumtaz K, Hamid S, Jafri W. Endoscopic retrograde cholangiopancreaticography with or without stenting in patients with pancreaticbiliary malignancy, prior to surgery. Cochrane Database Syst Rev. 2007;(3): CD006001.
68. Mallinson CN, Rake MO, Cocking JB, et al. Chemotherapy in pancreatic cancer: results of a controlled, prospective, randomised, multicentre trial. Br Med J. 1980;281(6255):1589-1591.

69. Kelsen D, Hudis C, Niedzwiecki D, et al. A phase III comparison trial of streptozotocin, mitomycin, and 5-fluorouracil with cisplatin, cytosine arabinoside, and caffeine in patients with advanced pancreatic carcinoma. Cancer. 1991;68(5):965-969.

70. Cullinan S, Moertel CE, Wieand HS, et al. A phase III trial on the therapy of advanced pancreatic carcinoma. Evaluations of the Mallinson regimen and combined 5-fluorouracil, doxorubicin, and cisplatin. Cancer. 1990;65(10):2207-2212.

71. Fung MC, Ishiguro H, Takayama S, Morizane T, Adachi S, Sakata T. Survival benefit of chemotherapy treatment in advanced pancreatic cancer: a meta-analysis. Proc Am Soc Clin Oncol. 2003;22:1155.

72. Grunewald R, Kantarjian H, Keating MJ, Abbruzzese J, Tarassoff P, Plunkett W. Pharmacologically directed design of the dose rate and schedule of 2',2'-difluorodeoxycytidine (Gemcitabine) administration in leukemia. Cancer Res. 1990;50(21):6823-6826.

73. Tempero M, Plunkett W, Ruiz Van Haperen V, et al. Randomized phase II comparison of dose-intense gemcitabine: thirty-minute infusion and fixed dose rate infusion in patients with pancreatic adenocarcinoma. J Clin Oncol. 2003;21(18):3402-3408.

74. Poplin E, Feng Y, Berlin J, et al. Phase III, randomized study of gemcitabine and oxaliplatin versus gemcitabine (fixed-dose rate infusion) compared with gemcitabine (30-minute infusion) in patients with pancreatic carcinoma E6201: a trial of the Eastern Cooperative Oncology Group. J Clin Oncol. 2009;27(23):3778-3785.

75. Louvet C, Andrè T, Lledo G, et al. Gemcitabine combined with oxaliplatin in advanced pancreatic adenocarcinoma: final results of a GERCOR multicenter phase II study. J Clin Oncol. 2002;20: 1512-1518.

76. Louvet C, Labianca R, Hammel P, et al. Gemcitabine in combination with oxaliplatin compared with gemcitabine alone in locally advanced or metastatic pancreatic cancer: results of a GERCOR and GISCAD phase III trial. J Clin Oncol. 2005;23(15):3509-3516.

77. Colucci G, Labianca R, Di Costanzo F, et al. A randomized trial of gemcitabine $(\mathrm{G})$ versus $\mathrm{G}$ plus cisplatin in chemotherapy-naive advanced pancreatic adenocarcinoma: The GIP-1 (Gruppo Italiano Pancreas GOIM/GISCAD/GOIRC) study. 2009 ASCO Annual Meeting. J Clin Oncol. 2009;27 Suppl 15. Abstract 4504.

78. Nieto J, Grossband ML, Kozuch P. Metastatic pancreatic cancer 2008: is the glass less empty? Oncologist. 2008;13(5):562-576.

79. Moore MJ, Goldstein D, Hamm J. Erlotinib plus gemcitabine compared with gemcitabine alone in patients with advanced pancreatic cancer: A phase III trial of the National Cancer Institute of Canada Clinical Trials Group. J Clin Oncol. 2007;25:1960-1966.

80. Heinemann V, Boeck S, Hinke A, Labianca R, Louvet C. Meta-analysis of randomized trials: evaluation of benefit from gemcitabine-based combination chemotherapy applied in advanced pancreatic cancer. BMC Cancer. 2008;8:82.

81. Heinemann V, Labianca R, Hinke A, Louvet C. Increased survival using platinum analog combined with gemcitabine as compared to single-agent gemcitabine in advanced pancreatic cancer: pooled analysis of two randomized trials, the GERCOR/GISCAD intergroup study and a German multicenter study. Ann Oncol. 2007;18(10):1652-1659.

82. Wang X, Ni Q, Jin M, et al. Gemcitabine or gemcitabine plus cisplatin for in 42 patients with locally advanced or metastatic pancreatic cancer. Zhonghua Zhong Liu Za Zhi. 2002;24(4):404-407.

83. Colucci G, Giuliani F, Gebbia V, et al. Gemcitabine alone or with cisplatin for the treatment of patients with locally advanced and/or metastatic pancreatic carcinoma: a prospective, randomized phase III study of the Gruppo Oncologia dell'Italia Meridionale. Cancer. 2002; 94(4):902-910.

84. Xie de R, Liang HL, Wang Y, Guo SS. Meta-analysis of inoperable pancreatic cancer: gemcitabine combined with cisplatin versus gemcitabine alone. Chin J Dig Dis. 2006;7(1):49-54. 
85. Cartwright TH, Cohn A, Varkey JA. Phase II study of oral capecitabine in patients with advanced or metastatic pancreatic cancer. J Clin Oncol. 2002;20:160-164.

86. Herrmann R, Bodokg G, Ruhstaller T, et al. Gemcitabine plus capecitabine compared with gemcitabine alone in advanced pancreatic cancer: a randomized, multicenter, phase III trial of the Swiss Group for Clinical Cancer Research and the Central European Cooperative Oncology Group. J Clin Oncol. 2007;25(16):2212-2217.

87. Xiong HQ, Rosenberg A, LoBuglio A, et al. Cetuximab, a monoclonal antibody targeting the epidermal growth factor receptor, in combination with gemcitabine for advanced pancreatic cancer: a multicenter phase II trial. J Clin Oncol. 2004;22(13):2610-2616.

88. Oettle H, Petzer U, Stieler J. Oxaliplatin/Folinic acid/5-fluoroouracil [24h] (OFF) plus best supportive care versus best supportive care alone (BSC) in second-line therapy of gemcitabine-refractory advanced pancreatic cancer (CONKO-003). Proc Am Soc Clin Oncol; 2005. Abstract 4031.

89. Strimpakos A, Saif MW, Syrigos KN. Pancreatic cancer: from molecular pathogenesis to targeted therapy. Cancer Metastasis Rev. 2008;27(3):495-522.

90. Iannitti D, Dipetrillo T, Akeman P, et al. Erlotinib and chemoradiation followed by maintenance erlotinib for locally advanced pancreatic cancer: A phase I study. Am J Clin Oncol. 2005;28:570-575.

91. Epelbaum R, Schnaider J, Gluzman A. Erlotinib as a single-agent therapy in patients with advanced pancreatic cancer. Presented at: the ASCO Gastrointestinal Cancer symposium; 2007; Orlando, Florida.

92. Kulke MH, Blaszkowsky LS, Ryan DP, et al. Capecitabine plus erlotinib in gemcitabine-refractory advanced pancreatic cancer. J Clin Oncol. 2007;25(30):4787-4792.

93. Philip PA, Mooney M, Jaffe D, et al. Consensus report of the National Cancer Institute clinical trials planning meeting on pancreas cancer treatment. J Clin Oncol. 2009;27(33):5660-5669.

94. Burtness BA, Powell M, Berlin J, et al. Phase II trial of irinotecan/docetaxel for advanced pancreatic cancer with randomization between irinotecan/ docetaxel and irinotecan/docetaxel plus C225, a monoclonal antibody to the epidermal growth factor receptor (EGF-r) : Eastern Cooperative Oncology [Meeting Abstracts]. J Clin Oncol. 2007;25 Suppl 18:4519.

95. Kindler HL, Friberg G, Singh DA, et al. Phase II trial of bevacizumab plus gemcitabine in patients with advanced pancreatic cancer. $J$ Clin Oncol. 2005;23(31):8033-8040.

96. Kindler HL, Niedzwiecki D, Hollis D, et al. A double-blind, placebo controlled randomized phase III gemcitabine + bevacisumab versus gemcitabien versus placebo. J Clin Oncol. 2007;25(185):4508.

97. Wallace JA, Locker G, Nattam S. Sorafenib plus gemcitabine for advanced pancreatic cancer: a phase II trial of the University of Chicago phase II consortium. J Clin Oncol. 2007;25:S 224.

98. O'Reilly EM, Niedzwiecki D, Hollis DR, et al. A phase II trial of sunitinib (S) in previously-treated pancreas adenocarcinoma (PAC), CALGB 80603. ASCO Annual Meeting. 2008.

99. Brune K, Hong SM, Li A, et al. Genetic and epigenetic alterations of familial pancreatic cancers. Cancer Epidemiol Biomarkers Prev. 2008;17(12):3536-3542.

100. Pietras K, Rubin K, Sjoblom T, et al. Inhibition of PDGF receptor signaling in tumor stroma enhances antitumor effect of chemotherapy. Cancer Res. 2002;62(19):5476-5484.

101. Mantoni TS, Schendel RR, Rödel F, et al. Stromal SPARC expression and patient survival after chemoradiation for non-resectable pancreatic adenocarcinoma. Cancer Biol Ther. 2008;7(11). [Epub ahead of print].

102. Hwang RF, Moore T, Arumugam T, et al. Cancer-associated stromal fibroblasts promote pancreatic tumor progression. Cancer Res. 2008;68(3):918-926.

103. Von Hoff DD, Ramanathan R, Borad M, et al. SPARC correlation with response to gemcitabine (G) plus nab-paclitaxel (nab-P) in patients with advanced metastatic pancreatic cancer: A phase I/II study. ASCO Annual Meeting. J Clin Oncol. 2009;27 Suppl 15. Abstract 4525.

104. Maitra A. Nab-paclitaxel targets tumor stroma and results, combined with gemcitabine, in high efficacy against pancreatic cancer models. AACR. 2009; Nov 17:C246.
105. Maréchal R, Mackay JR, Lai R, et al. Human equilibrative nucleoside transporter 1 and human concentrative nucleoside transporter 3 predict survival after adjuvant gemcitabine therapy in resected pancreatic adenocarcinoma. Clin Cancer Res. 2009;15(8):2913-2919.

106. Bergman AM, Adema A, Balzarini J, et al. Antiproliferative activity, mechanism of action and oral antitumor activity of CP-4126, a fatty acid derivative of gemcitabine, in in vitro and in vivo tumor models. Invest New Drugs. 2010: Jan 12. [Epub ahead of print].

107. Pecher G, Haring A, Kaiser L, Thiel E. Mucin gene (MUC1) transfected dendritic cells as vaccine: results of a phase I/II clinical trial. Cancer Immunol Immunother. 2002;51(11-12):669-673.

108. Hecht JR, Bedford R, Abbruzzese JL, et al. A phase I/II trial of intratumoral endoscopic ultrasound injection of ONYX-015 with intravenous gemcitabine in unresectable pancreatic carcinoma. Clin Cancer Res. 2003;9(2):555-561.

109. Wobser M, Keikavoussi P, Kunzmann V, Weininger M, Andersen MH, Becker JC. Complete remission of liver metastasis of pancreatic cancer under vaccination with a HLA-A2 restricted peptide derived from the universal tumor antigen survivin. Cancer Immunol Immunother. 2006;55(10):1294-1298.

110. Miyazawa M, Ohsawa R, Tsunoda T, et al. Phase I clinical trial using peptide vaccine for human vascular endothelial growth factor receptor 2 in combination with gemcitabine for patients with advanced pancreatic cancer. Cancer Sci. 2010;101(2):433-439.

111. Yang AS, Monken CE, Lattime EC. Intratumoral vaccination with vaccinia-expressed tumor antigen and granulocyte macrophage colony-stimulating factor overcomes immunological ignorance to tumor antigen. Cancer Res. 2003;63(20):6956-6961.

112. Jemal A, Siegel R, Ward E, et al. Cancer statistics, CA. Cancer J Clin. 2008;58(2):71-96.

113. Budiharto T, Haustermans K, Van Cutsem E, et al. A phase I radiation dose-escalation study to determine the maximal dose of radiotherapy in combination with weekly gemcitabine in patients with locally advanced pancreatic adenocarcinoma. Radiat Oncol. 2008;3:30.

114. Crane $\mathrm{CH}, \mathrm{AJ}$, Evans DB, et al. Is the therapeutic index better with gemcitabine-based chemoradiation than with 5-fluorouracil-based chemoradiation in locally advanced pancreatic cancer? Int $J$ Radiat Oncol Biol Phys. 2002;52(5):1293-1302.

115. McGinn CJ, Zalupski MM. Radiation therapy with once-weekly gemcitabine in pancreatic cancer: current status of clinical trials. Int J Radiat Oncol Biol Phys. 2003;56 Suppl 4:S10-S15.

116. Tabernero J, Macarulla T. Changing the paradigm in conducting randomized clinical studies in advanced pancreatic cancer: an opportunity for better clinical development. J Clin Oncol. 2009; 27(33):5487-5491.

117. Rocha Lima CM, Green MR, Rotche R, et al. Irinotecan plus gemcitabine results in no survival advantage compared with gemcitabine monotherapy in patients with locally advanced or metastatic pancreatic cancer despite increased tumor response rate.J Clin Oncol. 2004;22(18): 3776-3783.

118. Hashimoto K, Ueno H, Ikeda M, et al. Do recurrent and metastatic pancreatic cancer patients have the same outcomes with gemcitabine treatment? Oncology. 2009;77(3-4):217-223.

119. Bakkevold KE, Arnesjo B, Dahl O, Kambestad B. Adjuvant combination chemotherapy (AMF) following radical resection of carcinoma of the pancreas and papilla of Vater--results of a controlled, prospective, randomised multicentre study. Eur J Cancer. 1993;29A(5): 698-703.

120. Yeung RS, Weese JL, Hoffman JP, et al. Neoadjuvant chemoradiation in pancreatic and duodenal carcinoma. A phase II study. Cancer. 1993;72(7):2124-2133.

121. Kamthan AG, Morris JC, Dalton J, et al. Combined modality therapy for stage II and stage III pancreatic carcinoma. J Clin Oncol. 1997;15(8):2920-2927.

122. White R, Lee C, Anscher M, et al. Preoperative chemoradiation for patients with locally advanced adenocarcinoma of the pancreas. Ann Surg Oncol. 1999;6(1):38-45. 
123. Bajetta E, Di Bartolomeo M, Stani SC, et al. Chemoradiotherapy as preoperative treatment in locally advanced unresectable pancreatic cancer patients: results of a feasibility study. Int J Radiat Oncol Biol Phys. 1999;45(2):285-289.

124. Wanebo HJ, Glicksman AS, Vezeridis MP, et al. Preoperative chemotherapy, radiotherapy, and surgical resection of locally advanced pancreatic cancer. Arch Surg. 2000;135(1):81-87.

125. Kim HJ, Czischke K, Brennan MF, Conlon KC. Does neoadjuvant chemoradiation downstage locally advanced pancreatic cancer? J Gastrointest Surg. 2002;6(5):763-769.

126. Rau HG, Wichmann MW, Wilkowski R, et al. Surgical therapy of locally advanced and primary inoperable pancreatic carcinoma after neoadjuvant preoperative radiochemotherapy. Chirurg. 2002;73(2):132-137.

127. Aristu J, Canon R, Pardo F, et al. Surgical resection after preoperative chemoradiotherapy benefits selected patients with unresectable pancreatic cancer. Am J Clin Oncol. 2003;26(1):30-36.

128. Wilkowski R, Thoma M, Schauer R, Wagner A, Heinemann V. Effect of chemoradiotherapy with gemcitabine and cisplatin on locoregional control in patients with primary inoperable pancreatic cancer. World J Surg. Oct 2004;28(10):1011-1018.

129. Sa Cunha A, Rault A, Laurent C, Adhoute X, Vendrely V, Béllannée G, Brunet R, Collet D, Masson B. Surgical resection after radiochemotherapy in patients with unresectable adenocarcinoma of the pancreas J Am Coll Surg. 2005;201(3):359-365.

130. Delpero JR, Turrini O. Locally advanced pancreatic adenocarcinoma. Chemoradiotherapy, reevaluation and secondary resection. Cancer Radiother. 2006;10(6-7):462-470.

131. Adhoute X, Smith D, Vendrely V, et al. Subsequent resection of locally advanced pancreatic carcinoma after chemoradiotherapy. Gastroenterol Clin Biol. 2006;30(2):224-230.

132. Tink1 D, Grabenbauer GG, Golcher H, et al. Downstaging of pancreatic carcinoma after neoadjuvant chemoradiation. Strahlenther Onkol. 2009;185(557-66):557-566.

133. Berlin JD, Catalano P, Thomas JP, Kugler JW, Haller DG, Benson AB III. Phase III study of gemcitabine in combination with fluorouracil versus gemcitabine alone in patients with advanced pancreatic carcinoma: Eastern Cooperative Oncology Group Trial E2297. J Clin Oncol. 2002;20(15):3270-3275.

134. Reiss H, Helm A, Niedergethmann M, Schmidt-Wolf I, Moik M, Hammer C. A randomized, prospective, multicenter, phase III trial of gemcitabine, 5-fluorouracil (5-FU), folinic acid vs gemcitabine in patients with advanced pancreatic cancer. ASCO Annual Meeting. J Clin Oncol. 2005;23 Suppl 16. Abstract LBA4009.
135. Cunningham D, Chau I, Stocken DD, et al. Phase III randomized comparison of gemcitabine versus gemcitabine plus capecitabine in patients with advanced pancreatic cancer. J Clin Oncol. 2009;27(33):5513-5518.

136. Heinemann V, Quietzsch D, Gieseler F, et al. Randomized phase III trial of gemcitabine plus cisplatin compared with gemcitabine alone in advanced pancreatic cancer. J Clin Oncol. 2006;24(24):3 946-3952.

137. Stathopoulos GP, Syrigos K, Aravantinos G, et al. A multicenter phase III trial comparing irinotecan-gemcitabine (IG) with gemcitabine (G) monotherapy as first-line treatment in patients with locally advanced or metastatic pancreatic cancer. Br J Cancer. 2006;95(5) 587-592.

138. Abou-Alfa GK, Letourneau R, Harker G, et al. Randomized phase III study of exatecan and gemcitabine compared with gemcitabine alone in untreated advanced pancreatic cancer. J Clin Oncol. 2006; 24(27):4441-4447.

139. Reni M, Cordio S, Milandri C, et al. Gemcitabine versus cisplatin, epirubicin, fluorouracil, and gemcitabine in advanced pancreatic cancer: a randomised controlled multicentre phase III trial. Lancet Oncol. 2005;6(6):369-376.

140. Oettle H, Richards D, Ramanathan RK, et al. A phase III trial of pemetrexed plus gemcitabine versus gemcitabine in patients with unresectable or metastatic pancreatic cancer. Ann Oncol. 2005;16(10):1639-1645.

141. Bramhall SR, Rosemurgy A, Brown PD, Bowry C, Buckels JA. Marimastat as first-line therapy for patients with unresectable pancreatic cancer: a randomized trial. J Clin Oncol. 2001;19(15):3447-3455.

142. Bramhall SR, Schultz J, Nemunaitis J, Brown PD, Baillet M, Buckels JA. A double-blind placebo-controlled, randomised study comparing gemcitabine and marimastat with gemcitabine and placebo as first line therapy in patients with advanced pancreatic cancer. $\mathrm{BrJ}$ Cancer. 2002;87(2):161-167.

143. Moore MJ, Hamm J, Dancey J, et al Comparison of gemcitabine versus the matrix metalloproteinase inhibitor BAY 12-9566 in patients with advanced or metastatic adenocarcinoma of the pancreas: a phase III trial of the National Cancer Institute of Canada Clinical Trials Group J Clin Oncol. 2003;21(17):3296-3302.

144. Van Cutsem E, vandeVelde, Karasek P, et al. Phase III trial of gemcitabine plus tipifarnib compared with gemcitabine plus placebo in advanced pancreatic cancer. J Clin Oncol. 2004;22(8):1430-1438.
OncoTargets and Therapy

\section{Publish your work in this journal}

OncoTargets and Therapy is an international, peer-reviewed, open access journal focusing on the pathological basis of all cancers, potential targets for therapy and treatment protocols employed to improve the management of cancer patients. The journal also focuses on the impact of management programs and new therapeutic agents and protocols on

\section{Dovepress}

patient perspectives such as quality of life, adherence and satisfaction. The manuscript management system is completely online and includes a very quick and fair peer-review system, which is all easy to use. Visit http://www.dovepress.com/testimonials.php to read real quotes from published authors. 